
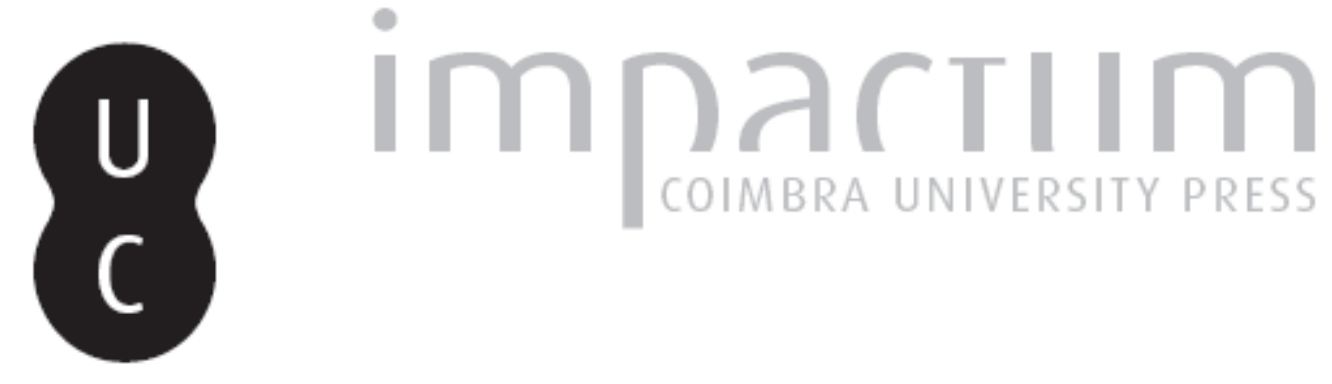

\title{
Ambiguidades na sintaxe grega das completivas de eij e o\{pw"
}

Autor(es): $\quad$ Sousa, Ana Alexandra Alves de Publicado por: Associação Portuguesa de Estudos Clássicos; Instituto de Estudos

URL $\quad$ URI:http://hdl.handle.net/10316.2/30424

DOI: $\quad$ DOI:http://dx.doi.org/10.14195/0872-2110_51_2

Accessed : $\quad$ 26-Apr-2023 12:28:41

A navegação consulta e descarregamento dos títulos inseridos nas Bibliotecas Digitais UC Digitalis, UC Pombalina e UC Impactum, pressupõem a aceitação plena e sem reservas dos Termos e Condições de Uso destas Bibliotecas Digitais, disponíveis em https://digitalis.uc.pt/pt-pt/termos.

Conforme exposto nos referidos Termos e Condições de Uso, o descarregamento de títulos de acesso restrito requer uma licença válida de autorização devendo o utilizador aceder ao(s) documento(s) a partir de um endereço de IP da instituição detentora da supramencionada licença.

Ao utilizador é apenas permitido o descarregamento para uso pessoal, pelo que o emprego do(s) título(s) descarregado(s) para outro fim, designadamente comercial, carece de autorização do respetivo autor ou editor da obra.

Na medida em que todas as obras da UC Digitalis se encontram protegidas pelo Código do Direito de Autor e Direitos Conexos e demais legislação aplicável, toda a cópia, parcial ou total, deste documento, nos casos em que é legalmente admitida, deverá conter ou fazer-se acompanhar por este aviso.

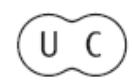




\section{Boletim de}

\section{Estudos Clássicos}

Associação Portuguesa de Estudos Clássicos Instituto de Estudos Clássicos

Coimbra

Junho de 2009 


\section{Ambiguidades na Sintaxe Grega daS COMPleTivas de $\in \ell$ E őt $\omega \varsigma$}

A análise que propomos para a compreensão das orações completivas conjuncionais partiu de dúvidas colocadas pelos alunos numa aula de língua grega. $\mathrm{O}$ objecto do nosso estudo serão os verbos que exprimem sentimento $\left(\theta \alpha u \mu \alpha \dot{\zeta} \zeta \omega\right.$, $\left.\alpha \gamma \alpha \nu \alpha \kappa \tau^{\prime} \epsilon \omega\right)$, por um lado, e os que exprimem preocupação,

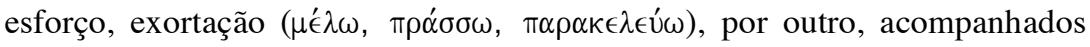
das conjunções $\epsilon \dot{l}$ e öt $\omega \varsigma$, respectivamente. A forma ambígua, incompleta e discordante como as gramáticas e os manuais de sintaxe apresentam os primeiros e as dificuldades sentidas pelos alunos na interpretação dos segundos levaram-nos a fazer esta reflexão.

Diz Humbert no primeiro parágrafo em que introduz as orações completivas:

"Aussi bien, des conjonctions qui sont le plus souvent affectées à

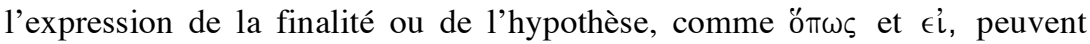
introduire une complétive, à condition que l'équivalence fondamentale soit

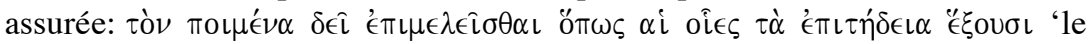
berger doit veiller à ce que ses brebis aient ce qui leur est nécessaire' pourrait être remplacé par: 'doit veiller aux besoins nécessaires du troupeau', de

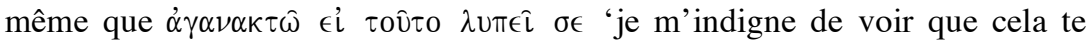
chagrine' n'est autre chose que 'je m'indigne de ton chagrin'" 1 .

Aparentemente a utilização das duas conjunções está explicada. No entanto, a questão começa a ficar confusa quando o linguista explica a oração causal, pois diz:

"Le lien entre subordonée et principale, si lâche quand la causale est introduite par ó $\tau \iota$ et $\dot{\omega} \varsigma$, peut se resserrer au point que la causale doit être considerée comme faisant fonction de complétive - c'est-à-dire indispensable

1 Syntaxe grecque, Paris, Klincksieck, 2004 (1972 ed. revue et augmentée), $\S 306$. 
à l'expression de la pensée principale - après nombre de verbes exprimant sentiments, comme l' admiration, ou le ressentiment $(\theta \alpha \nu \mu \alpha \dot{\zeta} \zeta \iota \nu, \alpha ٌ \chi \theta \in \sigma \theta \alpha \iota)$, l'envie ( $\phi \theta 0 \nu \in \hat{\imath} \nu)$, l'indignation ( $\alpha \gamma \alpha \nu \alpha \kappa \tau \in \hat{\imath} \nu)$, la honte ( $\alpha \hat{\imath} \sigma \chi \cup ́ v \in \sigma \theta \alpha \iota)$, etc. Le contenu de ces sentiments est exprimé par la causale, introduite par $\epsilon i$ ' 's'il est vrai que, puisque...",2.

Lido este parágrafo, perguntamo-nos se afinal se trata de uma oração causal ou de uma completiva.

$\mathrm{Na}$ demanda de uma solução, os alunos consultaram outras gramáticas, mas não resolveram o problema satisfatoriamente. Bornemann e Risch nada dizem sobre esta construção ${ }^{3}$, Smith integra-a nas orações causais ${ }^{4}$ e Goodwin insere $\theta \alpha \nu \mu \alpha \dot{\zeta} \zeta \omega$ єأ nas formas peculiares de oração condicional ${ }^{5}$, retomando-a na rubrica da oratio obliqua, por causa da possibilidade de nelas ocorrer o optativo oblíquo ou de subordinação na dependência de tempos

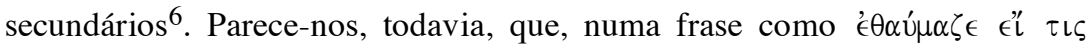

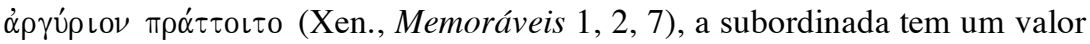
de complemento directo do predicado da oração principal, tanto mais que subordinada e subordinante não são permutáveis, como acontece com a prótase e a apódose no período hipotético ou com uma oração causal em relação à subordinante.

O facto de $\epsilon \dot{l}$ poder introduzir interrogativas indirectas ${ }^{7}$, por um lado, e o valor completivo interrogativo de certas orações introduzidas por $\theta \alpha u \mu \alpha ́ \zeta \omega$, com pronomes e advérbios interrogativos, por outro lado, poderão levar-nos a atribuir esse valor sintáctico à subordinada acima transcrita. Por exemplo a

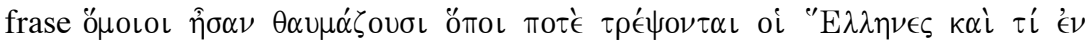

2 Ibid. $\$ 337$.

${ }^{3}$ Grieschiche Grammatik, $2^{\mathrm{a}}$ ed., Frankfurt a. Main, Verlag Moritz Diesterweg, 1978 (1970).

${ }^{4}$ Greek Grammar revised by G. Messing, Cambridge, Massachusetts, Harvard University Press, 1968 (1956), § 2247.

${ }^{5}$ Greek Grammar, London, St. Martin Press, 1983 (1894 new edition), § 1423.

$6 \mathrm{Ibid}$. 1502 . Mas, apesar de referir a construção quando explica o discurso indirecto, continua sempre a discorrer em termos de prótase e apódose. Convém salientar, de qualquer forma, que o tratamento dado por Goodwin ao discurso indirecto não distingue a completiva conjuncional da completiva interrogativa, como os exemplos deixam claro (cf. § 1487).

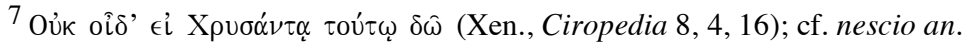




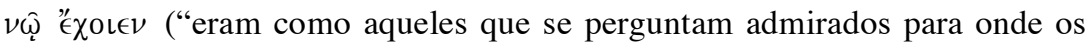
Gregos se voltarão e o que terão em mente", Xen., Anábase 3, 5, 13) apresenta duas completivas interrogativas indirectas introduzidas, a primeira, por um advérbio interrogativo de lugar, e a segunda, por um pronome interrogativo.

Como completiva interrogativa indirecta traduziríamos o exemplo de Xenofonte acima transcrito "perguntava admirado se alguém tinha exigido

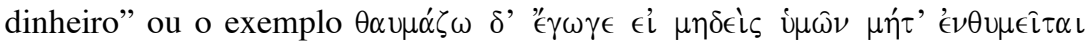
$\mu \eta^{\prime} \tau^{\prime}$ ó $\rho \gamma i \zeta \in \tau \alpha \iota$ (Dem. 4, 43), com que Goodwin exemplifica as "peculiar forms of conditional sentences", como "pergunto-me admirado se nenhum de vós se preocupa com isto nem se irrita". No entanto, o filólogo não as traduz com este matiz interrogativo, porque efectivamente isso trairia o sentido do texto. Repare-se, porém, que às vezes essa possiblidade existe. Uma frase

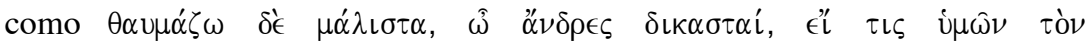

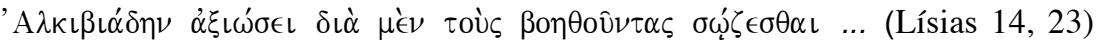
poderá ler-se "muito me admiro, senhores juízes, por algum de vós considerar digno salvar Alcibíades devido aos que o ajudam..." ou "pergunto-me verdadeiramente admirado, senhores juízes, se algum de vós considera digno salvar Alcibíades devido aos que o ajudam...". No entanto, nos dois exemplos anteriormente citados de Xenofonte e de Demóstenes, o valor é completivo sem matiz interrogativo: "admirava-se por alguém ter exigido dinheiro" e "admiro-me por nenhum de vós se peocupar com isto nem se irritar". O outro exemplo que Goodwin considera idêntico ao de Demóstenes apresenta o verbo $\alpha \gamma \alpha \nu \alpha \kappa \tau^{\prime} \in \omega$ e remete unicamente para a completiva conjuncional, não havendo a possibilidade de atribuir à frase um

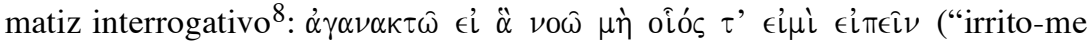
por não ser capaz de dizer o que penso", Platão, Laques 194 a) ${ }^{9}$. O paralelo deste exemplo com os anteriores leva-nos a optar pela tradução da frase acima transcrita de Lísias como completiva conjuncional.

A possibilidade de verbos como $\theta \alpha u \mu \alpha \dot{\zeta} \omega$ ou $\alpha \gamma \alpha \nu \alpha \kappa \tau \tau^{\prime} \epsilon \omega$ poderem aparecer com ő $\tau \iota$ é referida por Goodwin no parágrafo seguinte, que remete estas subordinadas para as causais ${ }^{10}$. Humbert omite esta construção e

8 Ibid. $\$ 1423$.

9 Repare-se, uma vez mais, que não se trata de prótase e apódose, já que a subordinada completa sintacticamente a subordinante, não se podendo alterar na tradução a sequência das orações.

10 Ibid. $\$ 1505$. 
Smith ${ }^{11}$ e Bornemann e Risch ${ }^{12}$ integram-na na oração causal. A ideia de

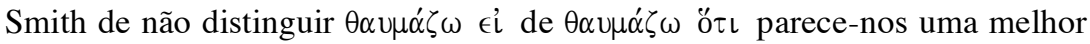
solução, dada a equivalência sintáctica das duas construções ${ }^{13}$.

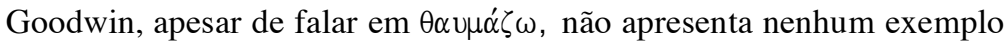
com este verbo, mas entre os exemplos da oração causal coloca um em que a conjunção é claramente completiva, exprimindo o verbo da principal uma

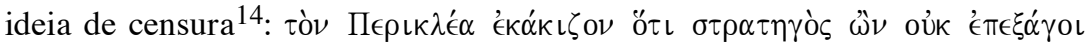
(Tuc. 2, 21), uma tradução como "censuravam Péricles, porque não os conduzia, apesar de ser general" pode induzir em erro, pois apresenta como complemento directo "Péricles" e a subordinada surge como a razão ou causa da censura, e não como complemento do verbo. Na realidade, o que importa não é o facto de a censura recair sobre Péricles, mas o facto de este não ter realizado uma determinada acção. Assim, ő $\tau$ introduz uma completiva com

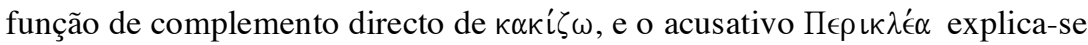
como um acusativo de antecipação ou proléptico, frequente nas completivas. A tradução que melhor espelha a sintaxe será "censuravam a Péricles o facto de não os conduzir, embora fosse general".

Idêntico a este exemplo é um outro que Goodwin insere no particípio

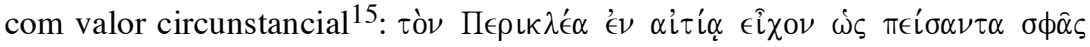
$\pi 0 \lambda \epsilon \mu \in \hat{\imath} \nu$ ("culpavam Péricles por os ter persuadido a entrar em guerra", Tuc. 2, 59). Neste caso o verbo é substituído por uma expressão perifrástica de

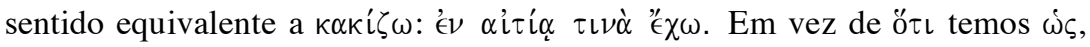
que se costuma associar a orações menos objectivas que se enquadram mais no plano da opinião ${ }^{16}$, como é o caso do exemplo citado. O uso do particípio

11 Ibid. $\$ 2248$.

12 Ibid. $\S 274$. Os linguistas alemães mencionam o verbo $\theta \alpha u \mu \alpha \zeta \zeta \omega$, mas em relação a $\alpha \gamma \alpha \nu \alpha \kappa \tau$ té $\omega$ falam apenas da construção com particípio (\$ 242), a qual, aliás, também associam a verbos de sentimento como $\theta \alpha u \mu \alpha ́ \zeta \omega$ (§ 181).

13 Smith utilizou a solução de Kühner e Gerth que apresentam como equivalentes estas duas construções; cf. Ausführliche Grammatik der griechischen Sprache, sweiter Teil: Satzlehre, Hannover-Leipzig, 1966 (1898), § 771 anotações 7. Aliás, estes dois linguistas alemães inserem ambas as construções nas orações substantivas. A confusão que se gerou a posteriori é que nos parece verdadeiramente surpreendente.

14 Ibid. $\$ 1506$.

15 Ibid. $\$ 1574$.

16 Cf. Humbert $\$ 308$. 
com valor completivo é uma construção típica da língua grega, que em nada contraria a ideia exposta.

A sintaxe latina não deixa dúvidas em relação à proximidade sintáctica que, por vezes, se verifica entre verbos de sentimento e os que exprimem "se fâcher, louer, féliciter, blâmer, remercier, reprocher, accuser"17. Além disso, a construção completiva com quod ou quia introduzida por este tipo de verbos permite-nos propor como interpretação sintáctica mais adequada a

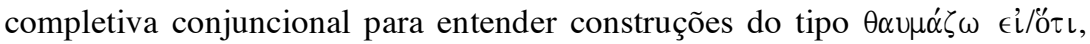

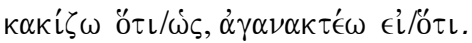

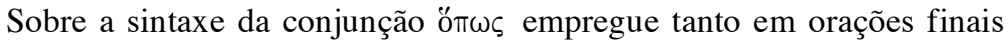
como em completivas conjuncionais reflecte-se uma ambivalência sintáctica digna de ser mencionada ${ }^{18}$. Não obstante a distância sintáctica entre a língua grega e a nossa, esta ambivalência recorda-nos a formulação em português de frases do tipo "ele pediu-me para fazer isto" e "ele pediu-me que fizesse isto". Ainda que "fazer isto" seja complemento directo de "ele pediu", não há dúvida de que a finalidade do pedido era que eu fizesse isto. Os Gregos evitavam esta confusão usando em ambas as situações a mesma conjunção. A questão coloca-se quando queremos classificar as subordinadas e aí os alunos reflectem a dificuldade que advém da formulação "pedir para" e "pedir que".

Humbert que, no já citado parágrafo, menciona o valor completivo da conjunção e o exemplifica com uma subordinada na dependência de '́㇒ா $\iota \mu \hat{\epsilon} \lambda \omega$, volta a mencionar este valor deixando claro que, apesar da tentativa, de algumas gramáticas, de associar o conjuntivo à ideia de fim e o indicativo futuro à ideia da completiva, os textos provam a precariedade desta teoria ${ }^{19}$. Acrescentaríamos que confirma a impossibilidade de distinguirmos estas orações o próprio facto de, em ambas, ser possível o optativo oblíquo ou de subordinação.

Sendo a conjunção a mesma, a distinção sintáctica faz-se analisando a

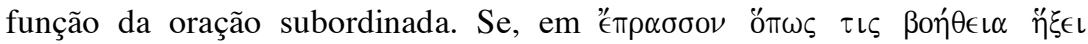
("conseguiram que chegasse ajuda", Tuc. 3,4 ) a subordinada completa o

17 Cf. A. Ernout \& Fr. Thomas, Syntaxe Latine, Paris, Éditions Klincksieck, 1972 (1951), § 304.

18 Para Kühner e Gerth a questão não se coloca, pois associam esta conjunção sempre à oração final, considerada como um segundo tipo das orações substantivas; cf. $\S 772$.

$19 \S 384$; cf. Goodwin $\S 1362, \S \S 1372-1375$; Smith $\S \S 2193-2206$ (sobretudo $\S 2201$ e $\S 2203), \S 2211, \S 2214$; Bornemann e Risch § 270. 


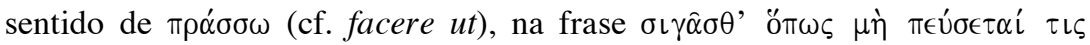
(“calai-vos, para que ninguém saiba", Ésq., Coéforas 265) a subordinada é

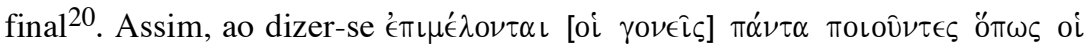

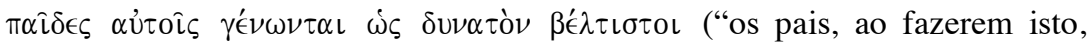
zelam por que as suas crianças se tornem o melhor possível”, Xen., Memoráveis 2, 2, 6), não obstante a finalidade visada pelos pais com a sua actuação, a circunstância de as crianças se tornarem o melhor possível é o objecto do zelo dos pais. A comparação com a sintaxe latina dissipa eventuais dúvidas, pois remete-nos para construções do tipo facio, curo, hortor... $u t^{21}$. Diríamos em conclusão que com verbos que exprimem esforço, cuidado, exortação e vontade a conjunção tem valor completivo.

ANA ALEXANDRA ALVES DE SOUSA

${ }^{20}$ Recordemos de novo a possibilidade de, neste último exemplo, alterar a ordem.

${ }^{21}$ Cf. Ernout, Thomas $\S 308$. 